\title{
Comparative Characteristics of Physical Development of Schoolchildren in Moscow and Kiev
}

\author{
Olga Yu. Milushkina, $\mathrm{PhD}, \mathrm{ScD}^{1 *}$; Natalia A. Skoblina, $\mathrm{PhD}, \mathrm{ScD}^{1}$; Natalia A. Bokareva, \\ $\mathrm{PhD}, \mathrm{ScD}^{1}$; Alina G. Platonova, $\mathrm{PhD}, \mathrm{ScD}^{2}$; Andrey A. Tatarinchik, $\mathrm{PG}^{1}$; \\ Vladimir G. Mikhaylov, $\mathrm{PhD}^{3}$; Denis M. Fedotov, $\mathrm{PhD}^{4}$ \\ 'Pirogov Russian National Research Medical University, Moscow, Russia \\ ${ }^{2}$ O.M. Marzeiev Institute for Public Health, Kiev, Ukraine \\ ${ }^{3}$ I.M. Sechenov First Moscow State Medical University, Moscow, Russia \\ ${ }^{4}$ Northern (Arctic) Federal University named after M.V. Lomonosov, Arkhangelsk, Russia
}

\begin{abstract}
The aim of this study was to find peculiarities in processes of growth and development of the child and adolescent in different megalopolises, Moscow and Kiev, on the background of various social and economic changes in society and standards of living of the child population. Comparison analysis of physical development of Moscow and Kiev children did not show statistically significant differences in body length except in boys aged between 10 and 16 years and in girls aged between 12 and 17 years. The changes in physical development of Kiev children demonstrate a domination of gracilization, accompanied by significant low values of body mass with high values of body length, especially in girls. The study showed that modern adolescents of both cities exceed their peers from previous generation in body length. Chest circumference in all ages of both sexes and body mass starting from 10 years of age were higher in adolescents from Moscow. We found a negative trend to the increase in the number of overweight Moscow children in the studied dynamics. (Int J Biomed. 2016; 6(4):279-282.)
\end{abstract}

Key Words: physical development • children • adolescents • body mass • body length

\section{Introduction}

Due to the incompleteness of the processes of growth and development of young people of school age, children and adolescents have an increased sensitivity to the adverse effects of exogenous factors, and, simultaneously, to the positive impact of preventive measures aimed at preserving and improving health in organized children's groups. ${ }^{[1-3]}$

The importance of studies of growth and development of the younger generation for childhood hygiene has been repeatedly noted by Russian scientists. ${ }^{[4-6,11]}$ One of the most essential directions of such studies is to establish changes in the physical development of children in "homogeneous groups," the characteristic of morphological and/or functional changes in the development of the child population.

*Corresponding author: Olga Yu. Milushkina, PhD, ScD, Head of the Department of Hygiene, Pirogov Russian National Research Medical University; Moscow, Russia.E-mail: olmilushkina@mail.ru
The aim of this study was to find peculiarities in processes of growth and development of the child and adolescent in different megalopolises, Moscow and Kiev, on the background of various social and economic changes in society and standards of living of the child population. We studied the interdependence of growth and development on children (between 8 and 17 years old) - the residents of the two capitals - by comparing the results of the two parallel studies.

\section{Material and Methods}

Our study was carried out by a natural hygienic experiment with the use of epidemiological studies in schools of Moscow and Kiev. Written informed consent was obtained from the child's parents. The work did not infringe on the rights and did not endanger the welfare of study subjects and met the requirements of biomedical ethics.

The participants were children and adolescents of the Moscow and Kiev regions who were born and lived in these 
cities (Russians, Belarusians, Ukrainians and also children from mixed marriages); 762 students from Moscow region and 612 from Kiev region were examined in the dynamics of learning from 1 st to 11 th grade.

We studied the physical development of children by unified methods with the use of standard tools,[4] as well as the somatometric indicators of physical development (body mass and body length, chest circumference). The evaluation of the physical development of Moscow schoolchildren was carried out by regional modified scales of regression of body mass (BM) on body length (BL), and in Kiev by agedsex regression scales of BM on BL. In fact, the principle of building these standards is identical, but in each state they are approved by the Ministry of Health alone.

The statistical analysis was performed using the statistical software «Statistica» (v6.0, StatSoft, USA). The mean (M) and standard error of the mean (SEM) were calculated. For data with normal distribution, inter-group comparisons were performed using Student's t-test. Pearson's correlation coefficient (r) was used to determine the strength of the relationship between the two continuous variables. A probability value of $P<0.05$ was considered statistically significant.

\section{Results}

It has been shown that physical development in the two cities is subject to the general regularities: sex dimorphism and heterochrony of development. However, children and adolescents of Moscow and Kiev were found to have some differences in the main physiometric indicators of physical development: the respiratory capabilities of children in Kiev in all age-sex groups were significantly lower than in Moscow groups. ${ }^{[7,10]}$

The studies showed that modern adolescents of both cities exceed their peers from previous generation in body length. Moscow children also have higher BM and chest circumference $(\mathrm{ChC})$ than their peers of the 1960s and 1980s, while modern children of Kiev have less BM and $\mathrm{ChC}$ than their peers of 30 to 50 years ago. ${ }^{[8,9]}$

The findings of the change in total body sizes in Moscow children show positive shifts in physical development, which may be associated with positive changes in the socioeconomic situation. The changes in physical development of Kiev children demonstrate a domination of gracilization, accompanied by significant low values of $\mathrm{BM}$ with high values of $\mathrm{BL}$, especially in girls.

Comparison analysis of physical development of Moscow and Kiev children didn't show statistically significant differences in BL except in boys aged between 10 and 16 years (Moscow children had significant higher values) and in girls aged between 12 and 17 years (Kiev girls had significant higher values) (Tables 1, 2).

The analysis of annual increase showed that in both cities girls had maximum BL increase from 11 to 12 years of age, and boys from 13 to 14 . In addition, it should be noted that the growth processes of the majority of Moscow girls are completed by age 16 (average annual increase from 16 to 17 was less than $1 \mathrm{~cm}$ ), while the growth processes of Kiev girls continue longer (average yearly increase from 16 to 17 years old is $1.82 \mathrm{~cm}$ ). Thus, we can suppose that definitive body sizes in Kiev girls will be greater than in Moscow girls.

Table 1.

Comparison analysis of physical development of Moscow and Kiev boys aged between 8 and 17

\begin{tabular}{|c|c|c|c|c|}
\hline Age (y) & City & $\mathrm{BL}(\mathrm{cm})$ & BM (kg) & $\mathrm{ChC}(\mathrm{cm})$ \\
\hline \multicolumn{5}{|l|}{ Boys } \\
\hline \multirow{3}{*}{8} & Moscow & $129.9 \pm 5.0$ & $26.5 \pm 3.6$ & $64.1 \pm 3.2$ \\
\hline & Kiev & $128.9 \pm 4.3$ & $27.2 \pm 3.2$ & $62.5 \pm 3.47$ \\
\hline & $P$ & $>0.05$ & $>0.05$ & $<0.05$ \\
\hline \multirow{3}{*}{9} & Moscow & $135.6 \pm 5.7$ & $31.1 \pm 4.0$ & $66.1 \pm 3.11$ \\
\hline & Kiev & $135.9 \pm 5.06$ & $31.6 \pm 4.2$ & $64.6 \pm 3.83$ \\
\hline & $P$ & $>0.05$ & $>0.05$ & $<0.05$ \\
\hline \multirow{3}{*}{10} & Moscow & $140.9 \pm 5.6$ & $35.4 \pm 4.8$ & $67.7 \pm 4.32$ \\
\hline & Kiev & $138.9 \pm 6.34$ & $32.7 \pm 4.8$ & $66.6 \pm 4.65$ \\
\hline & $P$ & $<0.05$ & $<0.05$ & $>0.05$ \\
\hline \multirow{3}{*}{11} & Moscow & $146.0 \pm 6.6$ & $40.0 \pm 5.9$ & $70.8 \pm 4.11$ \\
\hline & Kiev & $147.7 \pm 5.48$ & $39.7 \pm 5.8$ & $70.7 \pm 4.08$ \\
\hline & $P$ & $>0.05$ & $>0.05$ & $>0.05$ \\
\hline \multirow{3}{*}{12} & Moscow & $151.20 \pm 0.81$ & $44.50 \pm 1.07$ & $74.10 \pm 0.80$ \\
\hline & Kiev & $152.87 \pm 0.59$ & $40.95 \pm 0.62$ & $72.83 \pm 0.41$ \\
\hline & $P$ & $>0.05$ & $<0.01$ & $>0.05$ \\
\hline \multirow{3}{*}{13} & Moscow & $158.60 \pm 0.96$ & $50.90 \pm 1.36$ & $77.90 \pm 0.88$ \\
\hline & Kiev & $158.58 \pm 0.66$ & $47.77 \pm 0.58$ & $75.70 \pm 0.46$ \\
\hline & $P$ & $>0.05$ & $<0.05$ & $<0.05$ \\
\hline \multirow{3}{*}{14} & Moscow & $165.70 \pm 0.96$ & $53.60 \pm 1.31$ & $79.90 \pm 0.86$ \\
\hline & Kiev & $165.61 \pm 0.63$ & $52.62 \pm 0.67$ & $78.21 \pm 0.53$ \\
\hline & $P$ & $>0.05$ & $>0.05$ & $>0.05$ \\
\hline \multirow{3}{*}{15} & Moscow & $172.21 \pm 0.84$ & $63.31 \pm 1.46$ & $85.48 \pm 0.86$ \\
\hline & Kiev & $171.24 \pm 0.53$ & $59.53 \pm 0.78$ & $84.20 \pm 0.58$ \\
\hline & $P$ & $>0.05$ & $<0.05$ & $>0.05$ \\
\hline \multirow{3}{*}{16} & Moscow & $175.9 \pm 0.8$ & $67.5 \pm 1.6$ & $88.4 \pm 0.9$ \\
\hline & Kiev & $173.32 \pm 0.63$ & $58.99 \pm 0.87$ & $84.66 \pm 0.50$ \\
\hline & $P$ & $<0.05$ & $<0.001$ & $<0.001$ \\
\hline \multirow{3}{*}{17} & Moscow & $177.5 \pm 0.8$ & $69.7 \pm 1.6$ & $90.8 \pm 0.9$ \\
\hline & Kiev & $175.68 \pm 0.59$ & $63.48 \pm 0.83$ & $88.74 \pm 0.69$ \\
\hline & $P$ & $>0.05$ & $<0.001$ & $>0.05$ \\
\hline
\end{tabular}

The BM of modern children and adolescents from 10 years old was higher in Moscow children. Boys aged 10, $12-$ 13 and 15-17 and girls aged 10, 14-15 and 17 had statistically significant differences. $\mathrm{ChC}$ was higher in all age groups of both sexes in Moscow children, but boys aged 8-9, 13, and 16 and girls aged 8-9, and 16 had statistically significant differences.

The analysis of harmonicity of physical development of modern Moscow children aged between 8 and 17 years showed that $66.3 \%$ of participants had normal physical development. About $22.3 \%$ were underweight and $11.3 \%$ were overweight.

In comparison with previous studies, ${ }^{[6]}$ a clear trend to being overweight has appeared among Moscow children since 1980. In the $1980 \mathrm{~s}, 6.6 \%$ of children were overweight; in the 
$1990 \mathrm{~s}, 7.0 \%$; and in the $2000 \mathrm{~s}, 11.2 \%$. Consequently, over the last 30 years the number of children and adolescents who are overweight and obese has increased almost twice.

Table 2.

Comparison analysis of physical development of Moscow and Kiev girls aged between 8 and 17

\begin{tabular}{|c|c|c|c|c|}
\hline Age (y) & City & $\mathrm{BL}(\mathrm{cm})$ & BM (kg) & $\mathrm{ChC}(\mathrm{cm})$ \\
\hline \multicolumn{5}{|l|}{ Girls } \\
\hline \multirow{3}{*}{8} & Moscow & $129.2 \pm 5.6$ & $25.7 \pm 3.7$ & $62.5 \pm 3.35$ \\
\hline & Kiev & $127.9 \pm 4.51$ & $26.6 \pm 3.6$ & $61.3 \pm 3.37$ \\
\hline & $P$ & $>0.05$ & $>0.05$ & $<0.05$ \\
\hline \multirow{3}{*}{9} & Moscow & $134.5 \pm 5.6$ & $29.6 \pm 4.5$ & $65.1 \pm 3.32$ \\
\hline & Kiev & $134.7 \pm 4.64$ & $30.7 \pm 4.0$ & $63.9 \pm 3.39$ \\
\hline & $P$ & $>0.05$ & $>0.05$ & $<0.05$ \\
\hline \multirow{3}{*}{10} & Moscow & $140.2 \pm 6.0$ & $34.6 \pm 5.3$ & $67.5 \pm 4.10$ \\
\hline & Kiev & $137.4 \pm 5.16$ & $32.2 \pm 4.9$ & $65.7 \pm 4.50$ \\
\hline & $P$ & $>0.05$ & $<0.05$ & $>0.05$ \\
\hline \multirow{3}{*}{11} & Moscow & $146.2 \pm 7.2$ & $39.6 \pm 5.9$ & $70.1 \pm 4.59$ \\
\hline & Kiev & $146.4 \pm 5.58$ & $37.3 \pm 5.0$ & $69.0 \pm 4.63$ \\
\hline & $P$ & $>0.05$ & $>0.05$ & $>0.05$ \\
\hline \multirow{3}{*}{12} & Moscow & $153.20 \pm 0.64$ & $44.40 \pm 0.97$ & $74.60 \pm 0.79$ \\
\hline & Kiev & $155.13 \pm 0.59$ & $44.09 \pm 0.64$ & $73.14 \pm 0.47$ \\
\hline & $P$ & $<0.05$ & $>0.05$ & $>0.05$ \\
\hline \multirow{3}{*}{13} & Moscow & $159.40 \pm 0.60$ & $50.70 \pm 0.97$ & $78.40 \pm 0.66$ \\
\hline & Kiev & $160.06 \pm 0.64$ & $48.79 \pm 0.59$ & $78.26 \pm 0.45$ \\
\hline & $P$ & $>0.05$ & $>0.05$ & $>0.05$ \\
\hline \multirow{3}{*}{14} & Moscow & $162.60 \pm 0.64$ & $53.20 \pm 1.09$ & $80.40 \pm 0.67$ \\
\hline & Kiev & $161.99 \pm 0.43$ & $50.45 \pm 0.41$ & $79.83 \pm 0.41$ \\
\hline & $P$ & $>0.05$ & $<0.05$ & $>0.05$ \\
\hline \multirow{3}{*}{15} & Moscow & $164.25 \pm 0.5$ & $56.2 \pm 1.02$ & $82.10 \pm 0.6$ \\
\hline & Kiev & $163.38 \pm 0.49$ & $52.25 \pm 0.57$ & $81.04 \pm 0.40$ \\
\hline & $P$ & $>0.05$ & $<0.001$ & $>0.05$ \\
\hline \multirow{3}{*}{16} & Moscow & $164.63 \pm 0.53$ & $57.41 \pm 0.99$ & $82.71 \pm 0.61$ \\
\hline & Kiev & $165.16 \pm 0.53$ & $55.29 \pm 0.64$ & $84.38 \pm 0.41$ \\
\hline & $P$ & $>0.05$ & $>0.05$ & $<0.05$ \\
\hline \multirow{3}{*}{17} & Moscow & $164.52 \pm 0.63$ & $58.05 \pm 1.35$ & $83.47 \pm 0.80$ \\
\hline & Kiev & $166.98 \pm 0.45$ & $53.95 \pm 0.61$ & $83.04 \pm 0.45$ \\
\hline & $P$ & $<0.01$ & $<0.05$ & $>0.05$ \\
\hline
\end{tabular}

An increase in the prevalence of excess weight has been observed in modern children. In boys age 8 , it was $8.0 \%$; in girls, $5.6 \%$. In boys age 12 , it was $16.8 \%$; in girls, $11.0 \%$. the maximum prevalence of excess weight was noticed in boys age $15(17.0 \%)$ and in girls age 14(13.1\%). This trend was more expressed among boys from 8 to 15 years old: the incidence of overweight boys has increased 3 times. By the age of $17,13.8 \%$ of boys and $10.1 \%$ of girls were overweight.

The statistical analysis showed that the level of harmonicity of physical development is mainly kept in the dynamics of study. Pearson's contingency coefficient for boys and girls from 8 to 15 years old was $0.60(P<0.001)$, 15 to 17 years old was $0.73(P<0.001)$ and $0.58(P<0.002)$, respectively. About $18.6 \%$ of underweight boys changed to the group of normal physical development by 15 years old, $8.5 \%$ of boys with normal physical development moved into the underweight group, and $6.8 \%$ moved into the overweight group (Figure 1). Unfortunately, overweight boys from 8 to 17 years old remained in the overweight group. Thus, the boys' overweight group was replenished in the dynamics of maturity. The most dynamic changes were observed in underweight girls. By 15 years old, about $31 \%$ of girls change their group to normal physical development (Figure 2), 5.2\% of girls moved into the underweight group and 3.5\% - into the overweight group. As with the boys, the girls' overweight group was replenished in the dynamics of maturity.

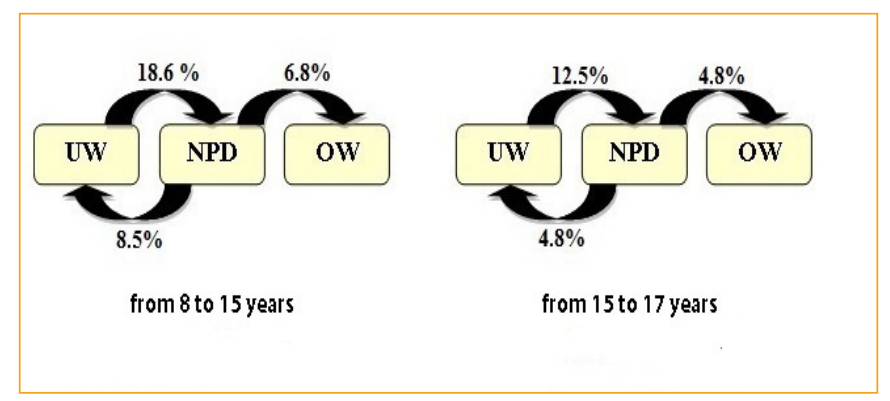

Fig. 1 .

UW - underweight boys; NPD - normal physical development; OW- overweight boys

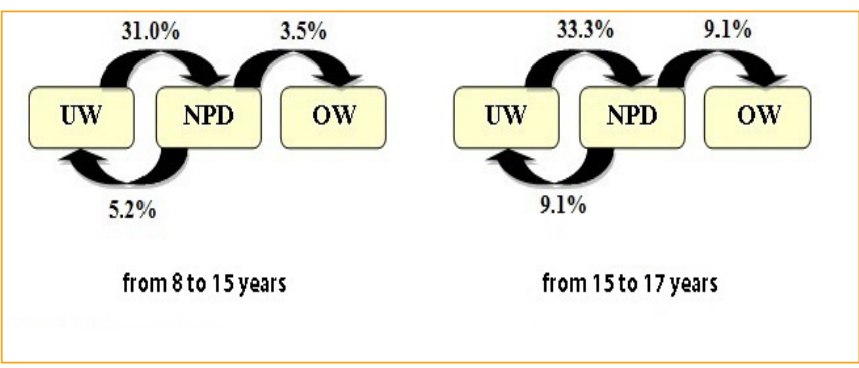

Fig. 2.

UW - underweight girls; NPD - normal physical development; $O W$ - overweight girls

\section{Conclusion}

In sum, the studies showed that modern adolescents from Moscow and Kiev did not have statistical differences in BL except for boys aged between 10 and 16 and for girls aged between 12 and 17. ChC in all ages of both sexes and BM starting from 10 years of age were higher in adolescents from Moscow. In most age groups of both sexes, the differences were statistically significant.

The analysis of harmonicity of physical development of Moscow children showed the prevalence of an overweight condition in the adolescent population for the last 30 years. In addition, we found a negative trend to the increase in the number of overweight Moscow children in the studied dynamics.

\section{Competing interests}

The authors declare that they have no competing interests. 


\section{References}

1. Baranov AA, Kuchma VR, Suhareva LM. The evaluation of health of children and adolescents at physical examinations: manual for doctors. Moscow: Dynasty; 2004, 168 pp. [in Russian].

2. Baranov AA, Kuchma VR, Suhareva LM. Medical and social aspects of adaptation modern adolescents to conditions of nurture, education and work activities. Moscow: GEOTARMedia; 2007, 352 pp. [in Russian].

3. Baranov AA, Sheplagina LA. The physiology of growth and development of children and adolescents (theoretical and practical questions). Moscow: GEOTAR-Media; 2006: Vol. 1, 432 pp. [in Russian].

4. Baranov AA, Kuchma VR, Yampolskaya UA. Research methods of physical development of children and adolescents in population monitoring. Manual for doctors. Moscow; 1999, 226 pp. [in Russian].

5. Godina EZ, Homyakova IA, Zadoroshnaya LV. Auxological research in the native country of M.V. Lomonosov. Messenger of Moscow University. XXIII series. Anthropology. 2011; 3:68-100. [in Russian].
6. Kuchma VR. Theory and practice of hygiene of children and adolescents at the turn of the millennium. Moscow: NCZD RAMN; 2001, 376 pp. [in Russian].

7. Kuchma VR, Skoblina NA, Platonova AG. Physical development of schoolchildren in Moscow and Kiev. Hygiene and Sanitation. 2012; 1:75-78[in Russian].

8. Kuchma VR, Skoblina. NA, Milushkina OU. Comparative retrospective analysis of physical and biological development of schoolchildren in Moscow. Hygiene and Sanitiation. 2012. 4:47-52. [in Russian].

9. Platonova AG. Physical development of city's schoolchildren in 30 years dynamic. The materials of III congress by Russian society of school and university medicine and health. Moscow: NCZD RAMN; 2012:312-4. [in Russian]. 10. Platonova AG, Skoblina NA, Bokareva NA, Milushkina OU. Comparative assessment of functional condition of schoolchildren in Moscow and Kiev. Hygiene and Sanitation. 2013; 3:74-7. [in Russian].

11. Skoblina NA. Methodological substantiation the assessment of physical development children in medical prevention system. Abstract of PhD Thesis. Moscow; 2008. [in Russian]. 